\title{
Hyaline membrane disease and intraventricular haemorrhage in small for gestational age infants
}

\author{
RENATO S PROCIANOY, JOSEPH A GARCIA-PRATS, JAMES M ADAMS, \\ ABRAHAM SILVERS, AND ARNOLD J RUDOLPH
}

Department of Pediatrics and Department of Medicine, Baylor College of Medicine, and Neonatology Service of the Texas Children's Hospital, Houston, Texas

SUMMARY 19 small for gestational age (SGA) infants with gestational ages $\leq 32$ weeks were matched with 19 appropriate for gestational age (AGA) preterm neonates with similar risk factors for intraventricular haemorrhage and hyaline membrane disease. Gestational age, 1- and 5-minute Apgar scores, type of delivery, survival rate, use of corticosteroids before delivery, sex, twinning, presence of premature rupture of membranes, and birth date were comparable in the two groups. Gestational age of both groups was $30( \pm 1 \cdot 8)$ weeks, and birthweights were $919( \pm 202)$ g (SGA group) and $1268( \pm 212) \mathrm{g}$ (AGA group). The incidences of hyaline membrane disease and intraventricular haemorrhage were different: 74 and $42 \%$ respectively for AGA neonates, 5 and $11 \%$ respectively for SGA infants. We suggest that a stressful environment in utero may enhance maturation and prevent hyaline membrane disease and intraventricular haemorrhage.

Hyaline membrane disease (HMD) and intraventricular haemorrhage (IVH) are common in very low birthweight infants and occur in association, except in very immature neonates. ${ }^{1-2}$ Necropsy studies suggest that HMD affects primarily appropriate for gestational age (AGA) infants, ${ }^{3-5}$ whereas it is uncertain whether IVH is more common in these same AGA babies. ${ }^{4}$ Early neonatal morbidity differs in AGA and small for gestational age (SGA) infants as a result of the different problems occurring in each group. ${ }^{6}$ The future neurological outcome of a very low birthweight infant also appears to be determined by the presence or absence of IVH. ${ }^{7-8}$ Therefore, it would be useful to know which babies are likely to be at high risk for IVH.

This retrospective study was performed to determine whether there is a difference in the occurrence of IVH and HMD in SGA infants of very low birthweights compared with AGA infants of very low birthweights with similar risk factors.

\section{Materials and methods}

Our study group comprised 239 infants weighing $\leq 1500 \mathrm{~g}$, gestational age $\leq 32$ weeks, admitted from January 1976 to June 1978 to the neonatal intensive care unit at Texas Children's Hospital in the first 24 hours of life. Of that group, 19 were classified as SGA based on birthweight $<10$ th centile on the intrauterine growth curve. The remaining 220 were classified as $\mathrm{AGA}^{9}$ (Table 1).

The following data were abstracted from charts of babies enrolled in the study: birthweight, gestational age, type of delivery, sex, 1- and 5-minute Apgar scores, use of corticosteroids before delivery, prolonged rupture of membranes for more than 24 hours, and presence or absence of HMD and IVH. Gestational age was determined by maternal dates and physical assessment. ${ }^{10}$ If physical criteria differed from the maternal dates by more than 2 weeks, the clinical assessment was used. The diagnosis of HMD was based on the presence of an expiratory grunt, chest wall retractions, oxygen requirements of $\mathrm{F}_{\mathrm{I}} \mathrm{O}_{2} \mathbf{0 . 5}$ or greater, the presence of a reticulogranular pattern on chest $x$-ray, a clinical course compatible with HMD, and necropsy data. IVH was diagnosed clinically by the presence of seizures, apnoea, sudden cardiovascular collapse, and sudden drop in haematocrit; it was confirmed by full fontanelle, bloody cerebrospinal fluid which did not clear, and posthaemorrhagic hydrocephalus, and by computerised tomography (CT) scan during the acute phase of the IVH (first 10 days of life), and necropsy data. All SGA infants were normal by physical examination except for the problems related to prematurity. Congenital infections were ruled out clinically and by laboratory studies.

To determine if an association existed between the 
occurrence of HMD or IVH and the birth groups AGA and SGA, the entire AGA and SGA groups were included initially in the comparison. However, there are large imbalances between AGA and SGA infant groups in the distribution of risk factors for HMD and IVH, and these imbalances could account for a significant association. To correct for the inequity in distribution, a matching scheme was devised. Each of 19 SGA infants was matched to a AGA infant with matching variables that are known to be risk factors for IVH and HMD. The selection was based on comparable gestational age, Apgar scores at 1 and 5 minutes, type of delivery, survival, use of corticosteroids 24-hours before delivery, sex, twinning (twin A with twin A; twin B with twin B), prolonged rupture of membranes, and birth date. The matching system was based on analysis of the risk factors for development of $\mathrm{HMD}^{11}$ and IVH. ${ }^{12}$ Proximity of birth date was included in the system to avoid the influence of different managements on the occurrence of IVH.

Statistical analysis of the data was performed by using Student's $t$ test and $\chi^{2}$ analysis where indicated.

\section{Results}

A general description of the whole population is given in Table 1. Table 1 shows that an AGA infant appears to have a higher risk for IVH and HMD. For the whole AGA population the survival rate was $65 \%$ with an occurrence of HMD and IVH of 51 and $44 \%$ respectively. The incidence of IVH before routine use of CT scan was $43 \%$. With the use of CT scan for diagnosis of IVH a similar incidence $(45 \%)$ was recorded.

The mean birthweight of AGA infants was greater than that of the SGA group at the same gestational age. However, 1- and 5-minute Apgar scores, type of delivery, twinning, survival rate, presence or absence of prolonged rupture of membranes, and sex were comparable between the two matched groups (Table 2). The survival rate was $89 \%$ in both groups. The pregnancy complication rate of the SGA infants was higher than that of the AGA group. In the

Table 1 Data of study population

\begin{tabular}{lcc}
\hline & $\begin{array}{l}\text { Appropriate for } \\
\text { gestational age } \\
(n=220)\end{array}$ & $\begin{array}{l}\text { Small for } \\
\text { gestational age } \\
(n=19)\end{array}$ \\
\hline Gestational age (weeks)* & $28.8 \pm 1.9$ & $30 \pm 1.8$ \\
Birthweight (g)* & $1103 \pm 235$ & $919 \pm 202$ \\
HMD & $110(51 \%)$ & $1(5 \%) \dagger$ \\
IVH & $97(44 \%)$ & $2(11 \%) \dagger$ \\
Survival & $143(65 \%)$ & $17(89 \%)$ \\
\hline
\end{tabular}

* Mean \pm SD. $\dagger P<0.001$.
Table 2 Data of study patients

\begin{tabular}{|c|c|c|}
\hline & $\begin{array}{l}\text { Appropriate for } \\
\text { gestational age } \\
(n=19)\end{array}$ & $\begin{array}{l}\text { Small for } \\
\text { gestational age } \\
(n=19)\end{array}$ \\
\hline $\begin{array}{l}\text { Gestational age (weeks)* } \\
\text { Birthweight (g)* }\end{array}$ & $\begin{aligned} 30 & \pm 1 \cdot 8 \\
1268 & \pm 212 \dagger\end{aligned}$ & $\begin{array}{r}30 \pm 1 \cdot 8 \\
919 \pm 202\end{array}$ \\
\hline \multicolumn{3}{|l|}{ Apgar score } \\
\hline 1 minute* & $\begin{array}{l}5 \cdot 2 \pm 2 \cdot 3 \\
7 \cdot 1 \pm 1 \cdot 4\end{array}$ & $\begin{array}{l}5 \cdot 2 \pm 2 \cdot 2 \\
6 \cdot 6 \pm 2 \cdot 0\end{array}$ \\
\hline \multicolumn{3}{|l|}{ Sex } \\
\hline $\begin{array}{l}\text { Male } \\
\text { Female }\end{array}$ & $\begin{array}{r}10 \\
9\end{array}$ & $\begin{array}{r}11 \\
8\end{array}$ \\
\hline \multicolumn{3}{|l|}{ Race } \\
\hline Black & 6 & 5 \\
\hline White & 13 & 13 \\
\hline Others & 0 & 1 \\
\hline $\begin{array}{l}\text { Premature rupture of } \\
\text { membranes }\end{array}$ & 7 & 5 \\
\hline \multicolumn{3}{|l|}{ Type of delivery } \\
\hline Vaginal & 14 & 14 \\
\hline Caesarean section & 5 & 5 \\
\hline Singleton births & 16 & 16 \\
\hline \multicolumn{3}{|l|}{ Twins } \\
\hline Twin A & 3 & 3 \\
\hline Twin B & 0 & $\mathbf{0}$ \\
\hline \multicolumn{3}{|l|}{ Corticosteroids given before } \\
\hline \multicolumn{3}{|l|}{ Outcome } \\
\hline Survivors & 17 & 17 \\
\hline Deaths & 2 & 2 \\
\hline
\end{tabular}

* Mean \pm SD. $\uparrow P<0 \cdot 001$.

Table 3 Occurrence of hyaline membrane disease (HMD) and intraventricular haemorrhage $(I V H)$

\begin{tabular}{lll}
\hline & $\begin{array}{l}\text { Appropriate for } \\
\text { gestational age } \\
(n=19)\end{array}$ & $\begin{array}{l}\text { Small for } \\
\text { gestational age } \\
(n=19)\end{array}$ \\
\hline HMD & $14(74 \%)$ & $1(5 \%)(\mathrm{P}<0.001)$ \\
IVH & $8(42 \%)$ & $2(11 \%)(\mathrm{P}<0.05)$ \\
\hline
\end{tabular}

SGA group these were: pre-eclampsia (4), chronic hypertension (1), discordant twins (1).

In the matched groups the occurrence of HMD and IVH was 74 and $42 \%$ respectively, whereas in the SGA group this was 5 and $11 \%$ (Table 3). Statistically, these figures were different.

\section{Discussion}

The usual occurrence of HMD has been reported as $46 \%$ in infants $\leq 32$ weeks' gestational age ${ }^{13}$ whereas for IVH it is $43 \%$ in infants with birthweights $\leq 1500$ g. $^{14} 92 \%$ of all IVH in premature infants is reported in babies $\leq 32$ weeks' gestational age. ${ }^{15}$ Our series gave the same figures. When we analysed our whole population (AGA + SGA infants) the presence of $\mathrm{HMD}$ was $47 \%$ and that of IVH $41 \%$.

In a previous study we found that the presence of HMD and IVH differs according to maturity of the infants. ${ }^{2}$ In the more mature AGA preterm infants (birthweight 1001-1500 g) the occurrence of HMD is an important factor associated with the presence of IVH. However, in the very small AGA 
infants (birthweight $\leq 1000 \mathrm{~g}$ ) immaturity overshadows any other factor. ${ }^{1-2}$ It was suggested by Gluck and Kulovich ${ }^{16}$ that certain maternal diseases - such as pre-eclampsia, hypertensive renal disease, and diabetes class $\mathrm{D}, \mathrm{E}$, and $\mathrm{F}$-accelerate lung maturity. This finding suggested the possibility that in SGA infants there may be a lower incidence of HMD and consequently a lower incidence of IVH.

The comparison between the whole AGA group and the small sample of SGA infants was made more difficult by the imbalance in risk factors between both groups. Furthermore, the whole AGA group had a lower mean gestational age. A matching system following rigid criteria was used to deal with such inequities. Known risk factors from other studies for $\mathrm{HMD}^{11}$ and $\mathrm{IVH}^{12}$ were selected to be used for matching criteria. The resulting two groups were comparable in gestational age and risk for development of HMD and IVH. We are aware that our sample is small.

From our data we suggest that the likelihood of HMD and IVH in SGA infants $\leq 32$ weeks' gestational age is lower than in a control AGA infant group with similar risk factors. Intrauterine stress to the fetus in abnormal pregnancies may accelerate lung maturity. ${ }^{16}$ It is also known that the administration of corticosteroids to pregnant women before a premature delivery matures fetal lungs. ${ }^{17}$ However, it is not well established whether endogenous cortisol prevents HMD. ${ }^{18}$ The role of other hormones in the occurrence of HMD has been investigated also. ${ }^{19}$ At present we are not aware of biochemical data, obtained at birth, which may reflect the stressful environment experienced by SGA infants and its relationship with presence or absence of HMD. A clinical study has demonstrated that infants with accelerated lung maturity (measured by $\mathrm{L} / \mathrm{S}$ ratio) have accelerated neurological maturity at birth. ${ }^{20}$ Impaired autoregulation of the cerebral circulation has been suggested as an important finding in the occurrence of IVH in distressed preterm infants. ${ }^{21-23}$ We suggest that AGA infants could have a more immature autoregulation of the cerebral circulation than SGA infants. Pathological information comparing central nervous system maturity - that is, decreased germinal matrix or evidence of increased vascular integrity - between SGA and AGA infants is not available. An anatomical difference may also be a determinant in the pathogenesis of IVH.

Thus, our study suggests that an SGA infant with the same risk factors for HMD and IVH as an AGA infant has a lower probability of developing these clinical entities. However, it does not determine whether a cause-effect relationship exists between HMD and IVH.

\section{References}

1 Wigglesworth J S, Davies P A, Keith I H, Slade S. Intraventricular haemorrhage in the preterm infant without hyaline membrane disease. Arch Dis Child 1977; 52: 447-51.

2 Garcia-Prats J A, Procianoy R S, Adams J M, Rudolph A J. The role of hyaline membrane disease in low birthweight infants who develop intraventricular hemorrhage (abstract). Pediatr Res 1979; 13 : 524.

3 Federick J, Butler N R. Certain causes of neonatal death. I. Hyaline membranes. Biol Neonate 1970; 15: 229-95.

4 Federick J, Butler N R. Certain causes of neonatal death. II. Intraventricular haemorrhage. Biol Neonate 1970; 15: 257-90.

5 De Sa D J. An analysis of certain factors in the aetiology of respiratory syndrome of the newborn. $\mathrm{Br} J$ Obstet Gynaecol 1969; 76: 148-53.

- Usher R H. Clinical and therapeutic aspects of fetal malnutrition. Pediatr Clin North Am 1970; 17 : 169-83.

7 Pape K E, Buncic R J, Ashby S, Fitzhardinge P M. The status at two years of low-birthweight infants born in 1974 with birth weights of less than $1001 \mathrm{gm}$. J Pediatr 1978; 92: 253-60.

8 Procianoy R S, Garcia-Prats J A, Hittner H M, Adams J M, Rudolph A J. An association between retinopathy of prematurity and intraventricular hemorrhage in low birthweight infants (abstract). Pediatr Res 1979; 13 : 528.

9 Battaglia F C, Lubchenco L O. A practical classification of newborn infants by weight and gestational age. $J$ Pediatr 1967; 71: 159-63.

10 Dubowitz L M, Dubowitz V, Goldberg C. Clinical assessment of gestational age in the newborn infant. J Pediatr 1970; 77: 1-10.

11 Farrell P M, Avery M E. Hyaline membrane disease. Am Rev Respir Dis 1975; 111 : 657-88.

12 Volpe J J. Neonatal intracranial hemorrhage: pathophysiology, neuropathology, and clinical features. Clin Perinatol 1977; 4: 77-102.

13 Usher R H, Allen A C, McLean F H. Risk of respiratory distress syndrome related to gestational age, route of delivery, and maternal diabetes. Am J Obstet Gynecol $1971 ; 111$ : 826-32.

14 Papile L-A, Burstein J, Burstein R, Koffler H. Incidence and evolution of subependymal and intraventricular hemorrhage. A study of infants with birthweights less than 1500 grams. J Pediatr 1978; 92: 529-34.

15 Farwell $J$, Scott $D$ T. Intracranial hemorrhage in prematures: population characteristics, CSF findings, and factors related to outcome (abstract). Ann Neurol 1978 ; 4: 186.

16 Gluck L, Kulovich M V. Lecithin/sphingomyelin ratios in amniotic fluid in normal and abnormal pregnancy. Am J Obstet Gynecol 1973; 115: 539-46.

17 Liggins G C, Howie M B. A controlled trial of antepartum glucocorticoid treatment for prevention of the respiratory distress syndrome in premature infants. Pediatrics 1972; 50: 515-25.

18 Kauppila A, Koivisto M, Pukka M, Tuimala R. Umbilical cord and neonatal cortisol levels. Obstet Gynecol 1978; 52: 666-72.

19 Gluckman P D, Ballard P L, Kitterman J A, Kaplan S L, Grumbach $M$ M. Fetal prolactin and the respiratory distress syndrome (abstract). Pediatr Res 1978; 12: 524.

20 Gould J B, Gluck L, Kulovich M V. The relationship between accelerated pulmonary maturity and accelerated neurological maturity in certain chronically stressed pregnancies. Am J Obstet Gynecol 1977; 127: 181-6. 
21 Lou H C, Lassen N A, Friis-Hansen B. Low cerebral blood flow in hypotensive perinatal distress. Acta Neurol Scand 1977; 56: 343-52.

22 Lou H C, Lassen N A, Friis-Hansen B. Impaired autoregulation of cerebral blood flow in the distressed newborn infant. J Pediatr 1979; 94: 118-21.

23 Volpe J J. Cerebral blood flow in the newborn infant. Relation to hypoxic-ischemic brain injury and periventricular hemorrhage. J Pediatr 1979; 94: 170-3.

Correspondence to Dr Joseph A Garcia-Prats, Department of Pediatrics, Baylor College of Medicine, Texas Medical Center, 1200 Moursund Avenue, Houston, Texas 77030, USA.

Received 17 July 1979

\section{Commentary}

\section{J S WIGGLESWORTH}

\section{Hammersmith Hospital, London}

At first glance the results of this interesting study appear to conflict with the findings of several previous authors that babies dying with IVH tend to be small for gestational age (SGA). ${ }^{1-2}$ Careful examination of the data presented in this paper suggests that the conflict with studies based entirely on necropsy findings may be more apparent than real.

The authors have established clearly that their SGA group had a significantly lower incidence of both HMD and IVH than the AGA infants, and that these differences persisted when the SGA infants were compared with a subgroup of AGA infants matched for gestational age and other risk factors for IVH. However, at the mean gestation of $\mathbf{3 0}$ weeks recorded in the matched study groups, the hypoxia and hypercapnia associated with development of HMD may of themselves represent the most important 'risk' factors causing loss of autoregulation with resultant cerebral hyperperfusion and IVH. ${ }^{3}$ IVH is seldom found at necropsy in infants without HMD born at a gestational age of 30 weeks or more. ${ }^{4}$ From the analyses presented it is thus not possible to tell whether the low incidence of IVH in the SGA group was purely a consequence of biochemical maturation of the lungs by prenatal stress, or was related in part to a concomitant advance in maturation of structure or autoregulatory function in the brain.

In addition, the limitation of analysis to infants $\leq 1500 \mathrm{~g}$ birthweight has excluded from the study many AGA infants of 28-32 weeks' gestational age. This means that the AGA group may contain a high proportion. of relatively undergrown infants. This in no way detracts from the main finding that severely growth-retarded infants may be protected from developing IVH by the effects of chronic prenatal stress. It does however allow the possibility that less severe degrees of fetal growth impairment, not associated with advance in lung maturation, could increase susceptibility to IVH as indicated by previous studies. It would be interesting to know whether, among infants with HMD, those who developed IVH were of lower birthweight for gestation than those who did not. This might help to answer the outstanding question as to whether fetal growth retardation confers an increased or decreased risk of developing IVH when any effects on lung maturation are excluded.

\section{References}

1 Fedrick J, Butler N R. Certain causes of neonatal death. II. Intraventricular haemorrhage. Biol Neonate 1970; 15: 257-90.

2 Harcke H T, Naeye R L, Storch A, Blanc W A. Perinatal cerebral intraventricular hemorrhage. $J$ Pediatr 1972; 80: 37-42.

3 Pape K E, Wigglesworth J S. Haemorrhage, ischaemia, and the perinatal brain. Clinics in Developmental Medicine 69/70. London: Heinemann Medical, 1979: 144.

4 Wigglesworth J S, Keith I H, Girling D J, Slade S A. Hyaline membrane disease, alkali, and intraventricular haemorrhage. Arch Dis Child 1976; 51 : 755-62. 